Key words: ambient temperature; effects of moisture; frostbite; immersion foot; moisture; prevention; skin temperature; trench foot

\section{Ketamine and Lidocaine as Local Anesthetics in Minor Dermatological Surgery \\ Saarelainen IO, ${ }^{1}$ Larni HM, ${ }^{1,2}$ Kiistala $U^{1}$}

1. Department of Dermatology and

2. Department of Anesthesiology, Military Central Hospital, Helsinki, Finland

Ketamine with adrenaline was used as a local anesthetic for the removal of naevi, dermatofibromas, and verrucae in a double-blind study. ${ }^{1}$ Laser surgery was used in 10 and excision using a knife in 22 cases. The ketamine concentration employed varied between 12.5 and 20.0 $\mathrm{mg} / \mathrm{ml}$. The adrenaline concentration used was 10 microg $/ \mathrm{ml}$. The total doses of ketamine used per patient ranged from 12.5 to $30 \mathrm{mg}$. Anesthesia as tested using the pin prick, was obtained within 1 to 3 minutes after injection and lasted for up to 11 minutes.

In all patients, the injection of ketamine caused some smarting that lasted for a few to 15 seconds. Erythema always was observed in the injection area and this observation broke the double-blind code. Extrapyramidal side-effects (light-headedness and dizziness) were reported by $18(56.2 \%)$ of our patients.

Conclusion: The use of ketamine as a local anesthetic is similar to the use of lidocaine even when the doses used are small. The only drawbacks of ketamine are its short duration and the high incidence of extrapyramidal sideeffects.

1. Larni HM, Saarelainen IO, Levænen J, Kiistala U, Pohjola J: Suction blistering applied to testing local analgo-anesthetic effect of ketamine. Ann Med Milit Fenn 1995;70:77-81.

Key words: extrapyramidal effects; ketamine; ketamineepinephrine; lidocaine; local anesthesia; minor surgical procedures

\section{Disposable and Continuous Use Heaters of Infusion Fluids for Field Use: A Preliminary Report}

Larni $H M,{ }^{1,2}$ Rajaniemi $M,{ }^{1}$ Levänen $J,{ }^{1}$ Pobjola $J,^{2}$ Kiistala $U^{3}$

1. Department of Anesthesiology,

2. Department of Pharmacy, and

3. Department of Dermatology, Military Central Hospital, Helsinki, Finland

Infusion fluids always should be administered at temperatures from $35^{\circ}$ to $40^{\circ} \mathrm{C}$. This is important especially under field conditions in cold or subzero weather and for hypothermic patients in all weather conditions.
In unexpected situations and exceptional environmental conditions, the readiness to infuse warm fluids especially in the field usually is lacking and preparations to do so may cause significant delays or, in the worst case, be impossible. In providing primary care to patients in the field, be it civilian or combat, the preparedness for infusing heated fluids should be instantaneous and continuous and usually requires special arrangements.

Two models for solving the problem of infusion of heated fluids are presented: 1) heating of the infusion fluid bag; and 2) heating the infusion fluid as it passes through the tubing. In the first model, the infusion bag is placed within a double-walled, soft plastic container, and the necessary heat is obtained from an exothermic reaction. The second model is battery-powered.

In the first model, heating of the infusion fluid is accomplished in less than two minutes. In the second model, heating of the infusion fluid flowing through the tubing is continuous, and in it, the heater can be placed close to the cannula. This possibility provides the advantage of preventing the heat loss that normally occurs as the fluid flows from the bag through the tubing.

Key words: field care; fluid warmers; fluid warming; hypothermia; intravenous fluids

\section{Junior Ice Hockey Players Exposed to Nitrous Oxides \\ Nilsson ME, Rydström P-O, Löfvenberg J, Starlander J Pulmonary Department, Östersund, Sweden}

Late on a Sunday evening, some parents noticed that their children were coughing following the ice hockey training. The local health information agency telephoned the Swedish Poison-Information Center where the suspicion arose immediately: that the children were expose to nitrous oxides while training in the ice hall. Using the telephone lists of the clubs who had been active that weekend, all of the players were asked to come in for evaluation. A nurse registered 187 persons between 22:30h and 01:00h. Those who were free of symptoms were evaluated in groups by a doctor every hour. They were asked to return if symptoms developed. No training was allowed during the first week following the episode. Those players with symptoms, 62 persons, were checked by four doctors: auscultation, peak expiratory flow measurement, pulse oximetry, blood pressure, and pulse rate were done.

Treatment: General and inhaled corticosteroids and in severe cases, oxygen was administered during the first 24-28 hours in the hospital. Training was not allowed to resume for 2-4 weeks depending on symptoms. Followup evaluations done four months after the incident will be presented.

Key words: athletics; corticosteroids; intoxication; nitrous oxide; oxygen 